Article

\title{
Empirical Study on the Relationship between Effective Following Behavior and Derived Creative Work Behavior: A Moderating Role of Perceived Organizational Support and Sustainable Leadership
}

\author{
Xiaoyan Wang ${ }^{1,2}$, Liren An ${ }^{1, *}$, Nosheena Yasir ${ }^{1, *} \mathbb{1}$, Nasir Mahmood ${ }^{3}$ and Ying Gu ${ }^{1}$ \\ 1 School of Economics and Management, Northwest University, Xi'an 710127, China; \\ wangxiaoyan2005@163.com (X.W.); guying@nwu.edu.cn (Y.G.) \\ 2 Student Affairs Department, Xi'an Aeronautical University, Xi'an 710077, China \\ 3 School of Management Sciences, Northwestern Polytechnical University, Xi'an 710072, China; \\ nasirmahmood@nwpu.edu.cn \\ * Correspondence: alr@nwu.edu.cn (L.A.); nosheena.yaqoob@yahoo.com (N.Y.)
}

\section{check for}

updates

Citation: Wang, X.; An, L.; Yasir, N.; Mahmood, N.; Gu, Y. Empirical Study on the Relationship between Effective Following Behavior and Derived Creative Work Behavior: A Moderating Role of Perceived Organizational Support and Sustainable Leadership. Sustainability 2021, 13, 5693. https://doi.org/ $10.3390 /$ su13105693

Academic Editor: Ladislav Mura

Received: 21 April 2021

Accepted: 12 May 2021

Published: 19 May 2021

Publisher's Note: MDPI stays neutral with regard to jurisdictional claims in published maps and institutional affiliations.

Copyright: (c) 2021 by the authors Licensee MDPI, Basel, Switzerland. This article is an open access article distributed under the terms and conditions of the Creative Commons Attribution (CC BY) license (https:// creativecommons.org/licenses/by/ $4.0 /)$.

\begin{abstract}
The leader of an organization and its members together constitute a binary structure of the main body of the organization and achievement of their goals. The existing literature mainly focuses on the characteristics and following behavior of members. Although the Leader-Member Exchange (LMX) theory uniquely explains the relationship between sustainable leaders and followers, it cannot as easily explain the creative work behavior of followers. This paper proposes that effective following behavior can stimulate the intrinsic motivation of followers and make this consistent with their work motivation, thereby producing creative work behavior and leading to the more effective achievement of organizational goals. Moreover, it demonstrates the internal relationships and mechanisms of action between effective following behavior and creative work behavior. Taking the two dimensions of effective following behavior as independent variables and the three dimensions of creative work behavior as dependent variables, a group of hypotheses were presented. The moderating role of the perceived organizational support and sustainable leadership in the relationship between effective following behavior and creative work behavior was demonstrated, and two groups of hypotheses were proposed. Data from 409 surveys, factor analysis, and multiple regression analysis were used to test the hypotheses. The empirical results show that in the organization the radical and incremental creative work behavior of the followers correlates positively with their active, participatory following behavior and the non-blind following behavior. The followers' non-creative routine work behavior correlates negatively with their active participatory following behavior and has no significant correlation with the non-blind following behavior. In conclusion, sustainable leadership and perceived organizational support can therefore strengthen the relationship between actively participating in following behavior and creative work behavior and weaken the relationship between non-blind following behavior and creative work behavior.
\end{abstract}

Keywords: effective following behavior; creative work behavior; perceived organizational support; sustainable leadership

\section{Introduction}

Climate change, cultural conflicts, political instability, technological innovations, economic integration, and disruptions caused by human migration require organizations to focus on local and global environments [1,2]. Sustainable development requires trade-offs of social, ecological, and environmental goals where employees may think and speak up differently to enhance their performance at the individual and organizational levels [3,4].

Leadership is a vital and key factor that promotes psychological safety [5]. 
Hence, the leader of the organization and its members (or followers) together constitute the binary structure of the main body of the organization [6]. Thus, the leaders and followers jointly define the functions of the organization and jointly achieve the goals of the organization [7]. Environmental dynamics, such as climate change, economic integration, and cultural conflicts, have led to the emergence of new leadership known as sustainability leadership [8,9]. Sustainable leadership takes into consideration a comprehensive scope of the complex interconnections among individuals, the business community, the natural environment, and the global demands where the organization takes care of its well-being by concerning social values, obtaining success in the long term based on strategic decision-making value, and preservation of the ecosystem [5]. Keeping in view all forces that formulate employee perceptions about their work environment, the most potent is considered to be leadership [8]. Sustainable leadership can play a role in the organization, which is determined by the following behavior of its followers. However, the traditional leadership and follower theory holds that followers are the appendages of organizational sustainable leadership and the means by which sustainable leaders achieve their organizational goals [10].

The leadership style theory focuses on the situation in which a sustainable leadership style is more effective for the development of organizational goals [11]. Therefore, leadership contingency theory and leadership situation theory mainly focus on matching a sustainable leadership style with the subordinates' ability and enthusiasm in specific situations [12]. The transformational leadership theory holds that sustainable leadership is a process of changing or transforming people, and it focuses on people's emotions, values, ethics, norms, and long-term goals in the development of social economies and environmental aspects; thereby, followers accomplish things beyond the expectations in the perspective of sustainability [13].

In the theory of sustainable leadership-centered dual organizations, there are various incentive theories [14]. When people study the innovative behavior of employees in an organization, they mainly focus on how sustainable leaders stimulate employee innovative behavior and investigate the influencing mechanism of sustainable leaders on employee innovative behavior [15]. Thus, they think that sustainable leaders are "role models" in the organization, and dual sustainable leadership stimulates employees' innovative behavior, which has a significant positive effect on their innovative behavior [16]. These are also traditional leadership theories, which mainly emphasize the role of leadership but generally ignore the positive role of the followers in the sustainability perspective.

However, other organizational theories have constantly proved that organizational members (leader's followers) play an active role in the process of achieving organizational goals [17]. A recent study reported that employees are the main body of organizational innovation and the implementers of innovation [18]. Li and coworkers defined the concept of the active innovation subject and developed the scale on the basis of the active innovation subject of scientific and technological personnel. They proposed that the innovative behavior of scientific and technological personnel is a type of planning behavior and that the endogenous attitude, self-efficacy, and innovation willingness of scientific and technological personnel have a positive effect on their innovative behavior [19].

There are two stages and two-way drivers in the generation of employees' active innovation behavior: internal value-driving (intrinsic motivation leading) and external value-driving (identity motivation leading) [20]. These studies emphasize the initiative innovation of employees but fail to explain the internal value drive and identity drive of employees and fail to put employees in the "dual subject" organization associated with sustainable leaders and followers. They also fail to explain what leads to intrinsic motivation and what unifies intrinsic value and identity motivation [21].

LMX (Leader-Member Exchange) theory discusses the exchange content between sustainable leaders and members [22], explains the hierarchy of followers in the organization, and explains that high-quality LMX contributes more to the organization [23]. However, it 
explains the followers' work behavior in the sense of exchange, and it is difficult to reveal the creative work behavior generated by the followers' intrinsic motivation [24].

Kelley's theory of effective following behavior provides only a measurement of followers' effective following behavior and effective followership, meanwhile, it fails to address the specific performance of effective following behavior in the organization, or the work behavior caused by it and does not specifically address followers' creative work behavior in the organization. Chen and colleagues theoretically proved that effective following behavior is planned behavior, and the following behavior as planned behavior has the characteristics of initiative and intrinsic motivation driving, which is reflected in the followers' work behavior [25].

Based on the above analysis, the questions raised in this paper are as follows: Since followers' effective following behavior is planned behavior, how is this reflected in their work behavior? How is this derived into different degrees of creative work behavior? How does the organizational climate together with the followers' effective following behavior affect their derived creative work behavior? Therefore, the first problem explored in this article is to use the effective following behavior of followers in the organization as an antecedent variable and the work behavior of employees as the outcome variable to theoretically demonstrate the internal relationship between the two. The second question to be studied in this paper is what dimensions of creative work behavior are derived from effective following behaviors as antecedents, and what is the relationship between different dimensions of effective following behavior and the different dimensions of creative work behavior? The third problem to be examined is how the organizational climate (such as sustainable leadership behavior and organizational support) plays a role between effective following behavior and the nature of creative work behavior of employees. In short, this paper attempts to establish a relationship model between the followers' effective following behavior (independent variable) and the derived creative work behavior (dependent variable) as well as sustainable leadership and organizational support and to collect relevant data for empirical tests.

\section{Analysis of the Relationship between Effective Following Behavior and Creative Work Behavior}

\subsection{The Concept of Effective Following Behavior}

Based on the TPB theory, Chen and co-workers demonstrated that following behavior attitudes, perceived following behavior norms, and perceived following behavior control were the main factors influencing the intention of following behavior and proposed that the rational following behavior of followers is an effective following behavior, which includes active participation in the achievement of organizational sustainable goals and non-blind behavior in interactions with leaders [25].

Kelley (1988) described this type of positive and effective following behavior as "playing an active role, having independent, critical thinking, and positive action characteristics, and being competent for the requirements of organizational tasks" [26]. Chaleff (1995) pointed out that followers are positive people who have the courage to take responsibility, challenge, and change, serve sustainable leaders, and adhere to moral behavior and that excellent sustainable leaders require the support of excellent followers, and followers should have the same status as sustainable leaders [27].

Kelley and Chaleff further indicated that effective followers have several basic qualities: First, they manage themselves well; second, they are committed to the sustainable goals of the organization; third, they build up their own capabilities and concentrate on achieving the greatest positive impact on the environment; and fourth, they are brave, honest and trustworthy $[26,27]$. This type of follower behavior is effective following behavior that shows a sense of ownership. In an organization, a follower is not only an active participant but also a person with an independent spirit and critical and independent thinking characteristics [27]. 


\subsection{Theoretical Analysis of Effective Following Behavior and Derived Creative Work Behavior}

The purpose of an organization is to achieve its goals. An organizational goal is achieved by the joint efforts of the dual structure subject of the organization; that is, the sustainable leaders and their followers interact in order to achieve the organizational goal, and they ultimately struggle together to achieve the organizational goal [28]. Therefore, the effective following behavior of followers to sustainable leaders will be derived into the followers' creative work behavior under the guidance of organizational goals.

Effective following behavior occurs when followers identify with organizational goals and sustainable leaders; therefore, this type of following behavior will be organically and effectively combined with organizational goals, thus, generating intrinsic motivation and transforming into creative work behavior [29]. The degree of effective following behavior of organization members is different, and the creative work behavior they choose is different. In this paper, the creative work behavior chosen by followers under effective following behavior is called derived creative work behavior.

A followers' effective following behavior internalizes into the followers' intrinsic motivation and externalizes into the followers' creative work behavior. As the followers' following motivations are different, the resulting creative work behaviors are different. Madjar et al. (2011) classified this into three types: radical creativity, incremental creativity, and routine non-creative performance [30].

As far as followers' creative work behavior is concerned, the existing studies have distinguished the factors of radical innovation and incremental innovation [31], distinguished the development activities and exploration activities [32], and considered that they are two independent dimensions [33]. Amabile and others also distinguished between incremental creative work relying on familiar algorithms and small adaptations and radical creative work relying on set heuristics and breakthroughs [34].

The routine work performance of followers refers to paying attention to quantity in their work, or "the effectiveness of employee execution in activities that contribute to the core technology of the organization" [35], which is shown by non-creative work behavior. For the convenience of expression and measurement, this paper regards the conventional non-creative work behavior as zero-creative behavior, which is a type of creative work behavior.

When followers interact with leaders, a "leader-member" exchange relationship is formed, based on "obeying the law of social exchange" and "the principle of distributive justice" [36] in "social exchange theory" [37]. A follower in an organization can, thus, obtain material rewards (wealth), spiritual rewards, enjoyment, and comfort (psychological wealth) as well as the identity, status, and reputation (social wealth). As a social exchange return, he or she will also give the organization a return under the principle of fairness. This exchange is manifested in the work behavior derived from the following behavior [38].

When different followers perceive different following behaviors and exchange values, their derived creative work behaviors can be completely different [39]. Some choose radical creative work behaviors in return for the organization, others choose incremental creative work behaviors in return for the organization, and others use routine non-creative work behaviors in return.

\subsection{The Relationship between Effective Following Behavior and Different Types of Creative Work Behavior}

The effective following behavior of followers in an organization is a concept composed of two dimensions: one is active participation behavior, and the other is non-blind following behavior [38]. The two behaviors are two attributes of followers; as the followers are different, their behaviors differ in size and strength. Therefore, the two dimensions lead to different levels of internal following motivation and social exchange, which are then translated into different creative work behaviors [40]. Ford (1996) was the first to explicitly use perception, motivation, knowledge, and ability as factors to decide whether to partici- 
pate in creative rather than habitual actions. He described how individual interpretations of multiple task areas affect their preferences for habitual and new behaviors [41].

The two dimensions of followers' effective following behavior, that is, active participation and non-blind obedience, form a mechanism that is stimulated to form a schema in the face of a working situation; this schema affects followers' interpretation of the problem and creation of meaning, thus affecting the process of their participation in creative action [33].

When followers have the same knowledge and ability, when they have high recognition of organizational goals, their explanation of task situation is related to their active participating following behavior [42]. Then, the degree of active participation has a positive effect on creative work behaviors, and a negative effect on a routine or non-creative work behaviors, while the direction and intensity of non-blind following behaviors acting on the three different types of work behaviors are different [43]. Therefore, the following hypothesis is proposed in this paper:

Hypothesis 1 (H1). Followers' effective following behavior (X) has a positive effect on their creative work behavior $(Y)$; however, the different dimensions of effective following behavior have different effects on the different dimensions of creative work behavior.

Based on social exchange theory and intrinsic motivation theory, when followers face a task, because of their confidence in their own expertise and perception of the task, they can take the available creative resources as an important factor to determine their creative participation [44]. In other words, followers will interpret a situation as requiring creativity, only when followers can interpret their own resources. If they take part in and take creative actions, then they will produce creative performance, which will reflect a return to the various support provided by the leader and the organization, and they will be willing to take radical creative behavior [45].

Ford [41] and Unsworth and Clegg [46] investigated whether there is an expectation mechanism for the use of resources, which makes the connection between extra efforts and expected performance credible, making followers more willing to adopt radical creative work behaviors when facing work tasks. Therefore, the following hypothesis is proposed:

Hypothesis 1.1 (H1.1). Followers' radical creative work behavior $\left(Y_{1}\right)$ is positively related to their active participating following behavior $\left(X_{1}\right)$ and non-blind following behavior $\left(X_{2}\right)$.

In addition, some followers show strong participation when they follow a sustainable leader and have a certain degree of non-blind following. The perceived rewards and expectations provided by the organization and sustainable leaders make them willing to make continuous improvements in their work according to the environment; in this way, they can repay the organizational support provided by the sustainable leaders [47].

These types of followers are more willing to actively participate in the work of sustainable leaders and organizations and make certain improvements, which means that they are influenced by the existence and experience of the social environment. According to the social anchors theory, the creativity of the group to which individuals belong can be perceived and imitated by the individuals, and an important feature of perception is that it is based on the extracted clues. Typically, individuals tend to those clues that are consistent with their own personality and character [41]. In terms of clues, the individual's tendency to obey includes loyalty, obedience, compliance, and so on [48].

Thus, these factors affect a follower's choice of environmental clues, thus hindering creativity to some extent. At the same time, the willingness to take risks may create a different perception perspective, sustainably leading to a shift toward creative behavior; however, this shift is incremental rather than radical [49]. Such followers actively participate, but usually have to consider the risk of failure; therefore, the effect of the participatory following on incremental creativity is weaker than that on radical creativity. Compared with radical creative work behavior, the independence of incremental creativ- 
ity is stronger, and the effect of the non-blind following is greater. Thus, the following hypothesis is proposed:

Hypothesis 1.2 (H1.2). There is a positive correlation between followers' incremental creative work behavior $\left(Y_{2}\right)$ and their active participating following behavior $\left(X_{1}\right)$; however, the correlation is weaker than that of radical creative work behavior; there is a positive correlation between followers' incremental creative work behavior $\left(Y_{2}\right)$ and their non-blind following behavior $\left(X_{2}\right)$; however, the correlation is stronger than that of radical creative work behavior.

Finally, another type of following behavior in an organization is that followers' identification with the sustainable leader and organization may be based on the pressure formed by society's views on loyalty and the established values and conventional obedience, while, as a driving factor, this pressure may not trigger more obedience and loyalty [38].

Such followers are more reluctant to "blindly follow" sustainable leaders; their behavior appears to be "independent", and they "go their own way". This restrains followers" desires to finish their work creatively, restrains their creative work behavior, and leads to more routine performance [31]. Therefore, we propose the following hypothesis:

Hypothesis 1.3 (H1.3). There is a negative correlation between followers' non-creative routine work behavior $\left(Y_{3}\right)$ and their active participating following behavior $\left(X_{1}\right)$; there is no significant correlation between followers' non-creative routine work behavior $\left(Y_{3}\right)$ and their non-blind following behavior $\left(X_{2}\right)$.

To summarize the study hypotheses, we have the following graphical model (see Figure 1):

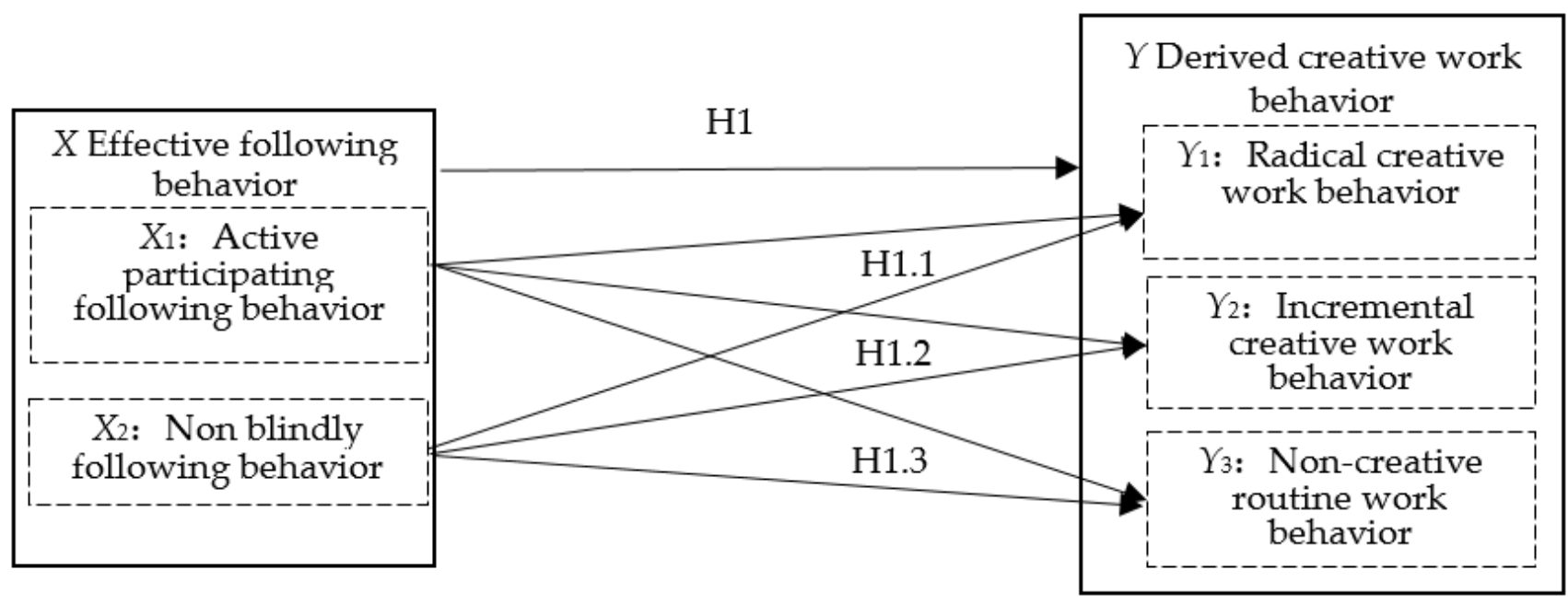

Figure 1. The relationship between effective following behavior and derived creative work behavior.

2.4. Analysis of Other Organizational Factors That Influence the Relationship between Following Behavior and Derived Work Behavior

The creative motivation in the organization, environmental factors, and external motivation of the organization also affect the creative behavior of employees [42]. These organizational environment factors guide, promote, adjust, bridge, or influence followers effective following behavior and creative work behavior. Many researchers have analyzed the role of perceived organizational support and sustainable leadership in employee work behavior. 


\subsubsection{The Moderating Role of Perceived Organizational Support}

Wilson and colleagues observed that different followers obtain different degrees of support in the organization, and thus organizational support plays a certain role in the process of transforming followers' effective following behavior into creative work behavior [50]. Researchers proposed that organizational support has an impact on employee work behavior, and particularly on employees' innovative behavior and that the size of the impact is related to the employees' perceived organizational support [51].

After Eisenberger, different scholars regarded perceived organizational support as an independent variable and concluded that perceived organizational support had a positive correlation with employee job performance [52]. Although these studies basically design perceived organizational support as an independent variable, the results show that perceived organizational support did affect the followers' work behavior.

When effective following behavior is regarded as the antecedent variable of work behavior, perceived organizational support will strengthen or weaken the influence of effective following behavior on work performance. In other words, if effective following behavior is considered, perceived organizational support can enhance or weaken an antecedent between employee effective following behavior and creative work behavior; that is, perceived organizational support is the moderator of the relationship between the two variables. Thus, we have the following hypothesis:

Hypothesis 2 (H2). Followers' perceived organizational support $\left(U_{1}\right)$ moderates the relationship between effective following behavior $(X)$ and derived work behavior $(Y)$.

The work behavior derived from followers' effective following behavior can be divided into three dimensions. Followers' perceived organizational support has different moderating effects on the relationship between the two dimensions of effective following behavior and the three dimensions of derived work behavior.

In terms of the relationship between perceived organizational support and followers' radical creative work behavior, organizational support itself can promote followers' radical creative work behavior [53]. That is, an interaction between perceived organizational support and followers' active participating following behavior. When followers feel organizational support, they are more willing to turn active participating following behavior into radical creative work behavior [54].

However, in a certain sense, perceived organizational support will produce the pressure of obedience on followers, which has a certain restrictive effect on followers' non-blind following behavior; this effect is negative to a certain extent because non-blind following behavior tends to work independently and autonomously [54]. Through the above analysis, the following hypothesis is proposed:

Hypothesis 2.1 (H2.1). Followers' perceived organizational support $\left(U_{1}\right)$ has a positive moderating effect on the relationship between active participating following behavior $\left(X_{1}\right)$ and radical creative work behavior $\left(Y_{1}\right)$ and a negative moderating effect on the relationship between non-blind following behavior $\left(X_{2}\right)$ and radical creative work behavior $\left(Y_{1}\right)$.

Followers' incremental creative work behavior is a progressive creative behavior. When they feel organizational support, they will also strengthen this type of creative behavior [55]. There is an interaction between perceived organizational support and active participating following behavior, and when followers feel organizational support, they are more willing to turn active participating following behavior into incremental creative work behavior; therefore, the interaction has a strengthening effect on incremental creative work behavior [54].

In addition, in a certain sense, perceived organizational support will produce the pressure of obedience on followers, which will also have a certain restrictive effect on followers' non-blind following behavior; this effect is negative to a certain extent because non-blind 
following behavior leads to intentions to work independently and autonomously [56]. Through the above analysis, the following hypothesis is proposed:

Hypothesis 2.2 (H2.2). Followers' perceived organizational support $\left(U_{1}\right)$ has a positive moderating effect on the relationship between active participating following behavior $\left(X_{1}\right)$ and incremental creative work behavior $\left(Y_{2}\right)$ and a negative moderating effect on the relationship between non-blind following behavior $\left(\mathrm{X}_{2}\right)$ and incremental creative work behavior $\left(Y_{2}\right)$.

The non-creative routine work behavior of followers is a type of behavior under the contract, and when followers face some tasks or work, they prefer to finish the work in the form of quantity. Such followers regard organizational support as part of their reward, welfare, or rights, they are passive in their work, and their participation is simply to complete the task. Their perceived organizational support is not strong [57], and they often regard organizational support as necessary. Followers with high perceived organizational support and with high participatory following behavior were found to be more reluctant to adopt non-creative routine work behavior [54].

Vice versa, followers with low participatory following behavior often cannot perceive organizational support and are more willing to adopt non-creative routine work behavior [58]. In other words, perceived organizational support can strengthen the relationship between participatory following behavior and non-creative routine work behavior [58]. Then, non-blind following behavior is the characteristic of such followers who work with quantity. As they always have a sense of being at the edge of the organization, perceived organizational support has no moderating effect on the relationship between non-blind following behavior and non-creative routine work behavior. Based on this, the following hypothesis is proposed:

Hypothesis 2.3 (H2.3). Followers' perceived organizational support $\left(U_{1}\right)$ has a negative reinforcement effect on the relationship between active participating following behavior $\left(X_{1}\right)$ and non-creative routine work behavior $\left(Y_{3}\right)$ and no significant moderating effect on the relationship between nonblind following behavior $\left(X_{2}\right)$ and non-creative routine work behavior $\left(Y_{3}\right)$.

\subsubsection{The Moderating Role of Sustainable Leadership}

Fischer and co-workers studied the components of individual creativity in an organization; they found that the individual creativity in the organization promoted the innovation of the organization, the organizational innovation environment or atmosphere improved the individual creativity, and the organizational atmosphere included sustainable leadership [42].

The connotation of sustainable leadership mainly emphasizes that leaders' sustainable inclusion of others is reflected in their behaviors, such as inviting followers to participate in decision-making discussions and decision-making implementation [34], recognizing other people's views and paying attention to other people's opinions or suggestions according to the sustainable environment. Later, Nembhard and Edmondson (2006) conducted a quantitative study on this concept [59], while Carmeli et al. (2010) extracted three dimensions of sustainable leadership: openness, accessibility, and availability according to the sustainable environment [60].

As far as followers' creative behavior is concerned, creation means not sticking to conventions, and failure is often its companion. When theoretically analyzed the success and failure of innovation, it pointed out that failure is that the work did not achieve the expected goal [61].

It can be seen that whether it is innovative or creative behavior, the result has the risk of failure, and the sustainable leader's response to the followers' success or failure will inevitably affect the followers' work behavior, and the leader's tolerance to failure affects the followers' decision-making of what type of work behavior to adopt. Sustainable leadership is a type of relationship between leaders and followers (or subordinates), which 
emphasizes the interaction and interdependence between sustainable leaders and followers, and emphasizes the tolerance, encouragement, and inclusion of sustainable leaders to followers and the environment.

In an organization, when followers perceive the sustainable characteristics of their leaders, they will adjust their work behavior. This adjustment is associated with and interacts with their participatory following behavior to strengthen or weaken their work behavior in a sustainability perspective. Non-blind following behavior may be an independent following behavior in a certain sense; therefore, perceived sustainable leadership does not necessarily positively strengthen the relationship between non-blind following behavior and work behavior.

Through the above analysis of the role of sustainable leadership and the psychological process of followers' work behavior, we propose the following hypothesis:

Hypothesis 3 (H3). Followers' perceived sustainable leadership $\left(U_{2}\right)$ moderates the relationship between effective following behavior $(X)$ and derived work behavior $(Y)$.

In a certain sense, followers' creative work behavior has an uncertainty of work results. When followers perceive leader sustainability, the pressure caused by the possible adverse effects of work uncertainty will be reduced, and thus they are more willing to adopt radical creative behavior in their work [62]. When a follower perceives the existence of sustainable leadership, this strengthens his behavior of participating in organizational work and doing a good job, which is more conducive to creative work [61]. At the same time, followers with high non-blind following behavior seldom perceive leader sustainability and often turn a blind eye to leadership behavior, which inhibits their creative work. In this way, the following hypothesis is proposed:

Hypothesis 3.1 (H3.1). Followers' perceived sustainable leadership $\left(U_{2}\right)$ has a positive moderating effect on the relationship between active participating following behavior $\left(X_{1}\right)$ and radical creative work behavior $\left(Y_{1}\right)$ and a negative moderating effect on the relationship between non-blind following behavior $\left(X_{2}\right)$ and radical creative work behavior $\left(Y_{1}\right)$.

Compared with radical creative work behavior, incremental creative work behavior is a type of progressive creative behavior, and its results are less uncertain; however, there is still some uncertainty [63]. Therefore, when followers perceive sustainable leadership, the pressure caused by the possible adverse effects of such small uncertainty in the work will be reduced, and they are more willing to adopt incremental creative behavior in their work [64].

When a follower perceives the existence of sustainable leadership, this strengthens their behavior of participating in organizational work and doing a good job, which is more conducive to creative work, and, in general, followers are more willing to adopt incremental creative work behavior [61]. In addition, followers with high non-blind following behavior seldom perceive leader sustainability and ignore leadership behavior, which also inhibits their incremental creative work [62]. Compared with radical creative work, this inhibition is stronger. The following hypothesis is proposed:

Hypothesis 3.2 (H3.2). Followers' perceived sustainable leadership $\left(U_{2}\right)$ has a positive moderating effect on the relationship between active participating following behavior $\left(X_{1}\right)$ and incremental creative work behavior $\left(Y_{2}\right)$ and a negative moderating effect on the relationship between non-blind following behavior $\left(X_{2}\right)$ and incremental creative work behavior $\left(Y_{2}\right)$.

In the organization, the non-creative routine work behavior of followers is a type of behavior under the contract. These followers' perception of sustainable leadership is not strong, and when they face tasks or work, they prefer to complete the work in the form of the environment [65]. When followers perceive the leadership as sustainable and their 
participatory following behavior is high, they are more reluctant to adopt non-creative routine work behavior and more willing to adopt creative work behavior [66].

Vice versa, followers with low participatory following behavior often cannot perceive the existence of inclusive leadership and are more willing to adopt non-creative routine work behavior [65]. In other words, perceived inclusive leadership can strengthen the relationship between participatory following behavior and non-creative routine work behavior. On the other hand, non-blind following behavior is the characteristic of such followers who work with quantity, and they always have the feeling of keeping a distance from the leader; therefore, sustainable leadership has no moderating effect on the relationship between non-blind following behavior and non-creative routine work behavior [67]. Thus, we propose the following hypothesis:

Hypothesis 3.3 (H3.3). Follower sustainable leadership $\left(U_{2}\right)$ has a negative reinforcement effect on the relationship between active participating following behavior $\left(X_{1}\right)$ and non-creative routine work behavior $\left(Y_{3}\right)$ and no significant moderating effect on the relationship between non-blind following behavior $\left(\mathrm{X}_{2}\right)$ and non-creative routine work behavior $\left(Y_{3}\right)$.

\subsubsection{Effective Following Behavior, Perceived Organizational Support, Sustainable} Leadership, and Creative Work Behavior

Through the above analysis, it can be seen that follower effective following behavior interacts with their perceived organizational support and sustainable leadership to derive the creative work behavior, thereby, obtaining the construct model shown in Figure 2.

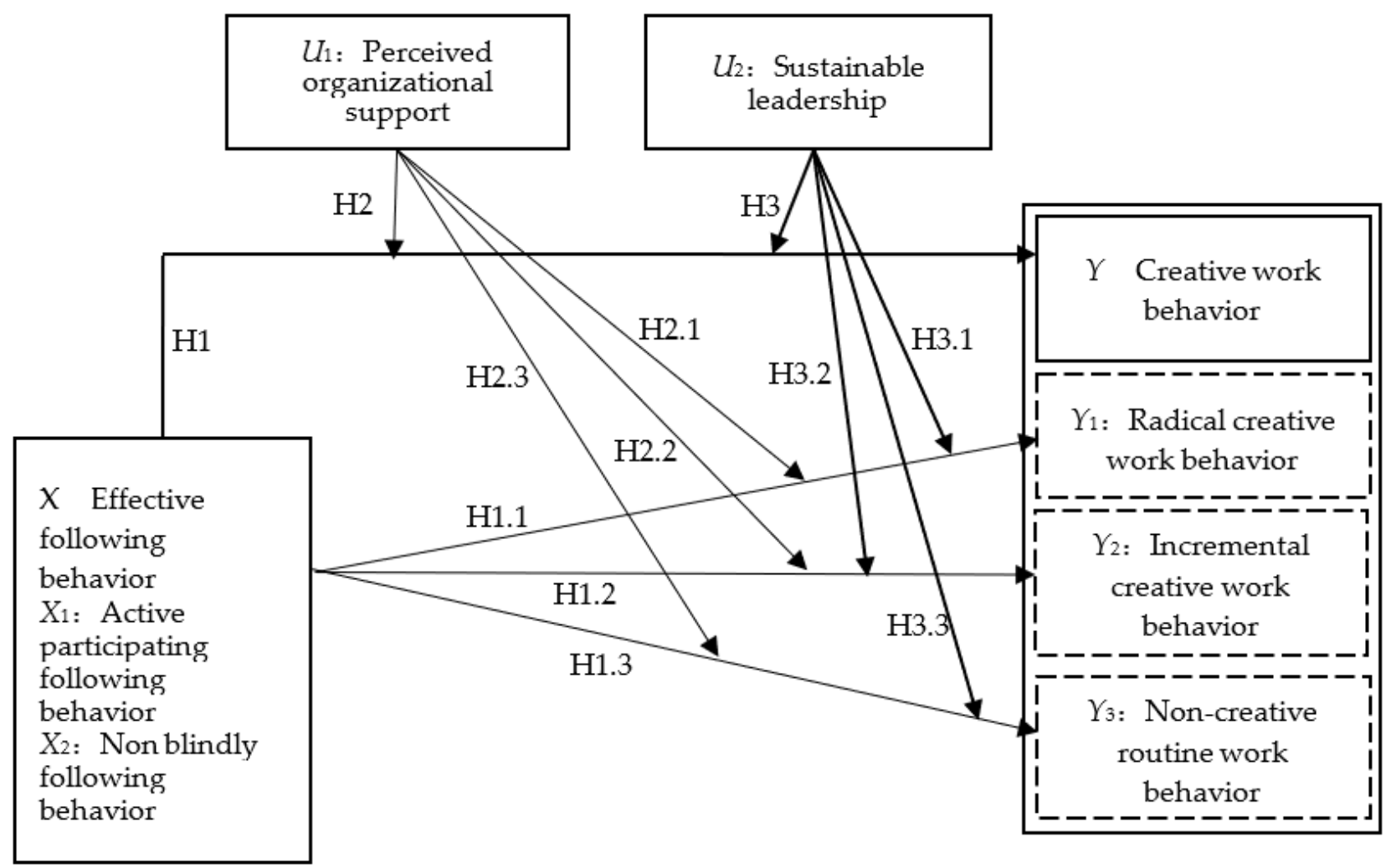

Figure 2. Construct model of the relationship among follower effective following behavior, perceived organizational support, sustainable leadership, and creative work behavior.

\section{Research Design and Data Collection}

As can be seen from Figure 2, this study involves four variables, including seven specific variables or dimensions. 


\subsection{Measurement Design of Effective Following Behavior (X)}

Effective following behavior is the follower's implementation of following behavior decision results driven by the following behavior intention. Following behavior is the degree of completion of the tasks assigned by the sustainable leader, the degree of support for the sustainable leader's views or decisions, and the behavior after understanding the sustainable leader's intention. Therefore, when designing the scale, we should first be consistent with the connotation of effective following behavior, and then, we should consider the cultural context of China. This paper mainly refers to Kelley's questionnaire, adopts two dimensions, and modifies its "critical" dimension to the "non-blindly follow" dimension.

The measurement of active participating following behavior $\left(X_{1}\right)$ is based on Kelley's [68] scale and Baker's [28] thoughts on improving the effectiveness of following behavior. In the pre-test stage, 10 items were designed to measure the substantial following behavior. We initially surveyed 217 cases using the exploratory factor analysis method and ultimately determined six measurement items.

Similarly, the measurement design of non-blind following behavior $\left(X_{2}\right)$ is based on the bipolar dimension proposed by Kelley [68]: independent and critical thinking-dependent and non-critical thinking. After the Chinese contextualization (e.g., obedience, moderation, skill, etc.) of its 10 items, 217 cases were initially surveyed, and five measurement items were finally determined using exploratory factor analysis.

\subsection{Measurement Design of Creative Work Behavior ( $Y$ )}

The creative ideas of followers or employees in an organization can be small adaptations up to radical breakthroughs [69]. This study uses three dimensions that Amabile (1997) proposed when studying the work behavior of organizational employees: radical creative work behavior $\left(Y_{1}\right)$, incremental creative work behavior $\left(Y_{2}\right)$, and non-creative routine work behavior $\left(Y_{3}\right)$. These behaviors of followers are competing work behavior choices, and the three behaviors are orthogonal [30].

The measurement design of these three work behaviors mainly refers to the operational definitions of Amabile [70] and others [71,72]. This study initially surveyed 217 cases, the exploratory factor analysis method was used, and we finally determined four measurement items for radical creative work behavior $\left(Y_{1}\right)$, four measurement items for incremental creative work behavior $\left(Y_{2}\right)$, and four measurement items for non-creative routine work behavior $\left(Y_{3}\right)$.

\subsection{Measurement Design of Perceived Organizational Support and Sustainable Leadership}

Eisenberger (1986) considered perceived organizational support $\left(U_{1}\right)$ as a single dimension when he defined its operational definition and designed a scale composed of 36 items [51]. Then, Eisenberger (1990) used a scale of 18 items in the study of "the relationship between perceived organizational support and employees' efforts, commitment, and innovative behavior" [73]. McMillin (1997) improved and deepened Eisenberger's operational definition, and proposed three dimensions: intimate support, respect support, and instrumental support [74].

On this basis, we referred to the measurement designed by Lee Sang Hyun (2017) in the study of "perceived organizational support, organizational identity and service innovation behavior of employees in the financial services industry" [75], and then considered the behavioral characteristics of Chinese followers and did not consider the dimensions. This study designed 12 measurement items and initially surveyed 217 cases. The exploratory factor analysis showed that these 12 items had an internal consistency of measurement.

The measurement of sustainable leadership $\left(U_{2}\right)$ was based on the questionnaire of Nembhard and Edmondson (2006) and Carmeli et al. (2010), which emphasizes that sustainable leadership works together with followers and completes tasks together with followers $[59,60]$. Therefore, when designing measurement items, this paper gives more consideration to the content of work, especially the content of "fault tolerance". Initially, 
nine measurement items were designed, 217 cases were surveyed, and, finally, six measurement items were determined using exploratory factor analysis.

\section{Testing the Hypothesis of the Relationship between Effective Following Behavior and Creative Work Behavior}

Hypothesis testing involves the fitness of the model, the validity of the data itself, and the relationship between variables. Factor analysis was used to test the fitness of the model, KMO and Bartlett's test were used for sample adequacy test, Cronbach $\alpha$ coefficient was used to test the reliability, confirmatory factor analysis was used to test the common method bias, and multiple regression analysis was used to test the hypothesis of the relationship between variables.

\subsection{Goodness-of-Fit and Reliability Test of Measurement Model}

\subsubsection{Goodness-of-Fit Test}

There are four variables in this paper, which were tested by confirmatory factor analysis. The recommended acceptance of a considerable fit for a model requires that the obtained fit-indices ratio of the chi-square value to the $\mathrm{df}$ is 2.507 , and, according to the standard described by Marsh and However [76], and the goodness-of-fit statistic (GFI), the adjusted goodness-of-fit statistic (AGFI), relative fit index (RFI), and normed-fit index (NFI) should be greater than 0.900 [77]. For alternative indices, the comparative fit index (CFI) should be greater than 0.900 , the root mean square error of approximation (RMSEA) should be less than 0.080 , and the root mean square residual (RMR) should be less than 0.050 [78]. As shown in Table 1, the test results of the measurement model goodness-of-fit.

Table 1. Measurement Model Goodness-of-Fit Test.

\begin{tabular}{|c|c|c|c|c|c|c|c|c|c|c|}
\hline Index & $\chi^{2} / d f$ & RMR & GFI & AGFI & RMSEA & NFI & RFI & IFI & TFI & CFI \\
\hline Effective following behavior $X$ & 2.507 & 0.045 & 0.954 & 0.930 & 0.061 & 0.931 & 0.919 & 0.936 & 0.918 & 0.936 \\
\hline Followers' work behavior $Y$ & 2.08 & 0.047 & 0.953 & 0.928 & 0.065 & 0.923 & 0.905 & 0.944 & 0.927 & 0.943 \\
\hline $\begin{array}{c}\text { Followers' perceived } \\
\text { organizational support } U_{1}\end{array}$ & 2.284 & 0.038 & 0.928 & 0.908 & 0.075 & 0.937 & 0.923 & 0.955 & 0.945 & 0.955 \\
\hline $\begin{array}{c}\text { Followers' perceived } \\
\text { sustainable leadership } U_{2}\end{array}$ & 2.171 & 0.032 & 0.977 & 0.947 & 0.073 & 0.9968 & 0.947 & 0.978 & 0.963 & 0.978 \\
\hline Reference value & $1 \sim 3$ & $<0.05$ & $>0.90$ & $>0.90$ & $<0.08$ & $>0.90$ & $>0.90$ & $>0.90$ & $>0.90$ & $>0.90$ \\
\hline
\end{tabular}

As shown in Table 1, the goodness-of-fit of each measurement model of the four variables meets the requirements.

\subsubsection{Sample Adequacy Test}

The Kaiser-Meyer-Olkin (KMO) and Bartlett's tests were used, and the results are shown in Table 2. Table 2 shows that the sampling in this paper was in line with the requirements, and the KMO index reached 0.942 indicating that the sample size was sufficient.

Table 2. Kaiser-Meyer-Olkin (KMO) and Bartlett's test.

\begin{tabular}{lcc}
\hline \multicolumn{2}{c}{ Kaiser-Meyer-Olkin Measure of Sampling Adequacy } & $\mathbf{0 . 9 4 2}$ \\
\hline \multirow{3}{*}{ Bartlett's test of sphericity } & Approximate chi-square & $11,312.754$ \\
& df & 1540 \\
& Sig. & 0.000 \\
\hline
\end{tabular}

\subsubsection{Reliability Test}

Cronbach's $\alpha$ coefficient as proposed by Cronbach in 1951 was adopted to test the reliability. There were seven latent variables in this study, and the overall Cronbach's $\alpha$ coefficient was 0.917 [79]. The Cronbach's $\alpha$ coefficients of the seven latent variables are shown in Table 3. 
Table 3. Cronbach's $\alpha$ coefficients of the seven latent variables.

\begin{tabular}{ccc}
\hline Latent Variable & $\begin{array}{c}\text { Measurement Variable's } \\
\text { Number }\end{array}$ & $\begin{array}{c}\text { Cronbach's } \boldsymbol{\alpha} \\
\text { Coefficient }\end{array}$ \\
\hline$X_{1}$ Active participating following behavior & 6 & 0.894 \\
$X_{2}$ Non-blind following behavior & 5 & 0.821 \\
$Y_{1}$ Radical creative work behavior & 4 & 0.755 \\
$Y_{2}$ Incremental creative work behavior & 4 & 0.788 \\
$Y_{3}$ Non-creative routine work behavior & 4 & 0.774 \\
$U_{1}$ Perceived organizational support & 12 & 0.925 \\
$U_{2}$ Sustainable leadership & 6 & 0.850 \\
\hline
\end{tabular}

As shown in Table 3, the Cronbach's $\alpha$ coefficients of all latent variables were greater than 0.75 , which indicates that the scale used in this paper had high reliability and met the requirements of the reliability test.

\subsection{Validity Test of Measurement Model}

\subsubsection{Content Validity}

After the pre-measurement, seven related experts were organized to score and analyze the scale determined in this paper. The experts agreed that the content of the scale was consistent with the concept itself-that is, it had content validity.

\subsubsection{Convergent Validity and Discriminant Validity}

Confirmatory factor analysis was used to test the discriminant validity of the measurement variables. The results showed that the measurement items of each latent variable were well clustered on the same factor. Due to space limitations, the results of the factor analysis are not shown here.

Finally, the factor analysis method was used to analyze the convergent validity of each latent variable measurement model, and the factor loads of the measurement items all met the requirements. On the basis of the convergent validity, the AVE value of each measurement model was calculated, and its discriminant validity was tested [80]. The results showed that all measurement models had good discriminant validity.

\subsubsection{Common Method Bias}

There are four sources of common method bias: one is the same data source or the same raters; the second is caused by the characteristics of the questionnaire; the third is caused by the deviation of the questionnaire content; the fourth is caused by the deviation of the measurement environment. This paper mainly used the program control method and statistical test method to control and avoid the common method bias [81].

Using confirmatory factor analysis, a total of seven factors were extracted based on eigenvalues, and the cumulative variance of interpretation reached $60.432 \%$. Among them, the variance of the first factor was 16.911 , accounting for $30.198 \%$, which is less than $30.216 \%$ (i.e., half of $60.432 \%$ ) and is, thus, in line with the criteria proposed by Harman. Therefore, the data measured in this study showed that there was no common method bias [82].

\subsection{Test of the Direct Relationship between Effective Following Behavior and Followers' Work Behavior}

Hypothesis $\mathrm{H} 1$ shows that followers' effective following behavior positively promoted their creative work behavior; however, the different dimensions of following behavior and creative work behavior had different effects.

4.3.1. Test of the Relationship between Radical Creative Work Behavior and Effective Following Behavior (H1.1)

Table 4 shows that followers' radical creative work behavior was positively correlated with their active participating following behavior and non-blind following behavior, and 
the significance was very high-exceeding the level of $p=0.001$. That is, hypothesis H1.1 passed the test at the level of $p<0.001$.

Table 4. Radical Creative Work Behavior $\left(Y_{1}\right)$, Incremental Creative Work Behavior $\left(Y_{2}\right)$, NonCreative Routine Work Behavior $\left(Y_{3}\right)$, and Effective Following Behavior.

\begin{tabular}{|c|c|c|c|c|c|c|}
\hline & \multirow{2}{*}{ Model } & \multicolumn{2}{|c|}{ Unstandardized Coefficient } & \multirow{2}{*}{$\begin{array}{c}\begin{array}{c}\text { Standard } \\
\text { Coefficient }\end{array} \\
\text { Trial }\end{array}$} & \multirow[t]{2}{*}{$t$} & \multirow{2}{*}{ Sig. } \\
\hline & & B & $\begin{array}{c}\text { Standard } \\
\text { Error }\end{array}$ & & & \\
\hline \multirow{3}{*}{$Y_{1}$} & (Constant) & $8.657 \times 10^{-18}$ & 0.041 & - & 0.000 & 1.000 \\
\hline & $X_{1}$ & $0.203^{* * *}$ & 0.057 & 0.203 & 3.542 & 0.000 \\
\hline & $X_{2}$ & $0.396^{* * *}$ & 0.057 & 0.396 & 6.924 & 0.000 \\
\hline \multirow{3}{*}{$Y_{2}$} & (Constant) & $2.732 \times 10^{-17}$ & 0.041 & & 0.000 & 1.000 \\
\hline & $X_{1}$ & $0.169^{* *}$ & 0.057 & 0.169 & 2.977 & 0.003 \\
\hline & $X_{2}$ & $0.432^{* * *}$ & 0.057 & 0.432 & 7.594 & 0.000 \\
\hline \multirow{3}{*}{$Y_{3}$} & (Constant) & $1.361 \times 10^{-17}$ & 0.049 & - & 0.000 & 1.000 \\
\hline & $X_{1}$ & $-0.166^{*}$ & 0.068 & -0.166 & -2.449 & 0.015 \\
\hline & $X_{2}$ & -0.011 & 0.068 & -0.011 & -0.157 & 0.875 \\
\hline
\end{tabular}

4.3.2. Test of the Relationship between Incremental Creative Work Behavior and Effective Following Behavior (H1.2)

As shown in Table 4, followers' incremental creative work behavior was positively correlated with their active participating following behavior and non-blind following behavior, and the significance level was very high. Active participating following behavior reached the level of $p=0.003$, while non-blind following behavior exceeded the level of $p=0.001$. That is, hypothesis H1.2 was supported by the testing at the overall level of $p \leq 0.003$.

4.3.3. Test of the Relationship between Non-Creative Routine Work Behavior and Effective Following Behavior (H1.3)

Table 4 shows that there was a negative correlation between followers' non-creative routine work behavior and their active participating following behavior, with a significance level of $p<0.05$; there was a weak negative correlation between non-creative routine work behavior and non-blind following behavior, and this was not significant. That is, hypothesis H1.3 was supported in the current study.

Through the above three tests, we found that the two dimensions of effective following behavior indeed had different effects on the three dimensions of derived creative work behavior-that is, H1, H1.1, H1.2, and H1.3 were all supported in this study.

\subsection{Test of the Moderating Role}

Multiple regression models were established, and SPSS22 was used as the calculation tool to obtain the regression results.

4.4.1. Testing the Moderating Role of the Relationship between Radical Creative Work Behavior and Effective Following Behavior

As can be seen from Table 5: $U_{1}$ (perceived organizational support) and $U_{2}$ (sustainable leadership) had a positive moderating effect on the relationship between active participating following behavior $\left(X_{1}\right)$ and radical creative work behavior $\left(Y_{1}\right)$ - that is, at the 0.05 significance level, $U_{1}$ and $U_{2}$ strengthened the positive correlation between $X_{1}$ and $Y_{1} . U_{1}$ and $U_{2}$ had a negative moderating effect on the relationship between non-blind following behavior $\left(X_{2}\right)$ and radical creative work behavior $\left(Y_{1}\right)$. At the 0.05 significance level, $U_{1}$ and $U_{2}$ weakened the positive correlation between $X_{2}$ and $Y_{1}$. Thus, the hypotheses H2.1 and H3.1 were supported in the study. 
Table 5. The moderating Model Test Results of Radical Creative Work Behavior (Y1).

\begin{tabular}{cccccc}
\hline Model & Variable & B & Standard Error & $t$ & Sig. \\
\hline Moderator & $($ Constant $)$ & -0.003 & 0.047 & -0.073 & 0.942 \\
variable & $X_{1}$ & $0.171^{* *}$ & 0.064 & 2.654 & 0.008 \\
model 1: $U_{1}$ & $X_{2}$ & $0.367^{* * *}$ & 0.059 & 6.244 & 0.000 \\
perceived or- & $U_{1}$ & $0.127^{*}$ & 0.052 & 2.442 & 0.014 \\
ganizational & $U_{1}{ }^{*} X_{1}$ & $0.113^{*}$ & 0.059 & 1.915 & 0.050 \\
support & $U_{1}{ }^{*} X_{2}$ & $-0.119^{*}$ & 0.055 & -2.163 & 0.031 \\
\hline Moderator & $($ Constant $)$ & -0.009 & 0.044 & -0.209 & 0.834 \\
variable & $X_{1}$ & $0.172^{* *}$ & 0.063 & 2.753 & 0.006 \\
model 2: $U_{2}$ & $X_{2}$ & $0.366^{* * *}$ & 0.058 & 6.297 & 0.000 \\
sustainable & $U_{2}$ & $0.147^{* *}$ & 0.048 & 3.080 & 0.002 \\
leadership & $U_{2}{ }^{*} X_{1}$ & $0.110^{*}$ & 0.052 & 2.115 & 0.035 \\
\hline Note: ${ }^{*} p<0.05 .{ }^{* *} p<0.01 .{ }^{* * *} p<0.001$. & $-0.113^{*}$ & 0.051 & -2.216 & 0.028 \\
\hline
\end{tabular}

4.4.2. Testing the Moderating Role of the Relationship between Incremental Creative Work Behavior and Effective Following Behavior

As can be seen from Table 6: $U_{1}$ (perceived organizational support) and $U_{2}$ (sustainable leadership) had a positive moderating effect on the relationship between active participating following behavior $\left(X_{1}\right)$ and incremental creative work behavior $\left(Y_{2}\right)$ - that is, at the 0.05 significance level, $U_{1}$ and $U_{2}$ strengthened the positive correlation between $X_{1}$ and $Y_{2} \cdot U_{1}$ and $U_{2}$ had a negative moderating effect on the relationship between non-blind following behavior $\left(X_{2}\right)$ and incremental creative work behavior $\left(Y_{2}\right)$. At the 0.01 significance level, $U_{1}$ and $U_{2}$ weakened the positive correlation between $X_{2}$ and $Y_{2}$. Thus, the hypotheses $\mathrm{H} 2.2$ and $\mathrm{H} 3.2$ were supported in the study.

Table 6. The moderating Model Test Results of Incremental Creative Work Behavior (Y2).

\begin{tabular}{|c|c|c|c|c|c|}
\hline Model & Variable & B & Standard Error & $t$ & Sig. \\
\hline Moderator & (Constant) & 0.015 & 0.047 & 0.321 & 0.749 \\
\hline variable & $X_{1}$ & 0.154 * & 0.064 & 2.427 & 0.016 \\
\hline model 1: $U_{1}$ & $X_{2}$ & $0.390^{* * *}$ & 0.058 & 6.715 & 0.000 \\
\hline perceived or- & $U_{1}$ & $0.119 *$ & 0.052 & 2.288 & 0.022 \\
\hline ganizational & $U_{1} * X_{1}$ & $0.131 *$ & 0.056 & 2.339 & 0.017 \\
\hline support & $U_{1} * X_{2}$ & $-0.162^{* *}$ & 0.054 & -3.115 & 0.002 \\
\hline \multirow{6}{*}{$\begin{array}{l}\text { Moderator } \\
\text { variable } \\
\text { model } 2: U_{2} \\
\text { sustainable } \\
\text { leadership }\end{array}$} & (Constant) & 0.008 & 0.044 & 0.190 & 0.850 \\
\hline & $X_{1}$ & $0.135 *$ & 0.061 & 2.213 & 0.033 \\
\hline & $X_{2}$ & $0.394^{* * *}$ & 0.057 & 6.894 & 0.000 \\
\hline & $U_{2}$ & $0.175^{* * *}$ & 0.047 & 3.747 & 0.000 \\
\hline & $U_{2} * X_{1}$ & 0.112 * & 0.051 & 2.196 & 0.023 \\
\hline & $U_{2} * X_{2}$ & $-0.159 * *$ & 0.050 & -3.166 & 0.002 \\
\hline
\end{tabular}

4.4.3. Testing the Moderating Role of the Relationship between Non-Creative Routine Work Behavior and Effective Following Behavior

As can be seen from Table 7: $U_{1}$ (perceived organizational support) and $U_{2}$ (sustainable leadership) had a negative moderating effect on the relationship between active participating following behavior $\left(X_{1}\right)$ and non-creative routine work behavior $\left(Y_{3}\right)$ - that is, at the 0.05 significance level, $U_{1}$ and $U_{2}$ strengthened the negative correlation between $X_{1}$ and $Y_{3} . U_{1}$ and $U_{2}$ had no significant moderating effect on the relationship between non-blind following behavior $\left(X_{2}\right)$ and non-creative routine work behavior $\left(Y_{3}\right)$. Thus, the hypotheses $\mathrm{H} 2.3$ and $\mathrm{H} 3.3$ were supported in the study. 
Table 7. Moderating Model Test Results of Non-Creative Routine WORK behavior (Y3).

\begin{tabular}{cccccc}
\hline Model & Variable & B & Standard Error & $\boldsymbol{t}$ & Sig. \\
\hline Moderator & $($ Constant $)$ & 0.038 & 0.056 & 0.674 & 0.500 \\
variable & $X_{1}$ & $-0.167^{*}$ & 0.076 & -2.202 & 0.028 \\
model 1: $U_{1}$ & $X_{2}$ & 0.029 & 0.069 & 0.418 & 0.676 \\
perceived or- & $U_{1}$ & -0.097 & 0.062 & -1.575 & 0.116 \\
ganizational & $U_{1}{ }^{*} X_{1}$ & $-0.169^{*}$ & 0.070 & -2.419 & 0.016 \\
support & $U_{1}{ }^{*} X_{2}$ & 0.127 & 0.065 & 1.960 & 0.051 \\
\hline Moderator & $($ Constant & 0.034 & 0.053 & 0.653 & 0.514 \\
variable & $X_{1}$ & $-0.168^{*}$ & 0.075 & -2.261 & 0.024 \\
model 2: $U_{2}$ & $X_{2}$ & 0.022 & 0.069 & 0.319 & 0.750 \\
sustainable & $U_{2}$ & $-0.116^{*}$ & 0.057 & -2.034 & 0.043 \\
leadership & $U_{2}^{*} X_{1}$ & $-0.123^{*}$ & 0.062 & -1.980 & 0.048 \\
& $U_{2}^{*} X_{2}$ & 0.066 & 0.061 & 1.089 & 0.277 \\
\hline Note* ${ }^{*} p<0.05 * *<0.01 * * *<0.001$ & & &
\end{tabular}

Note: ${ }^{*} p<0.05 .{ }^{* *} p<0.01 .{ }^{* * *} p<0.001$.

\section{Research Results and Discussion}

\subsection{Hypothesis Test Results and Discussion on the Direct Relationship between Effective} Following Behavior and Creative Work Behavior

\subsubsection{Test Results}

The H1.1 test results show that active participating following behavior $\left(X_{1}\right)$ and nonblind following behavior $\left(X_{2}\right)$ had positive effects on radical creative work behavior $\left(Y_{1}\right)$. The marginal contribution of $X_{1}$ was 0.203 , and the marginal contribution of $X_{2}$ was 0.396 . The results show that, for radical creative work behavior, the marginal contribution of active participating following behavior and the marginal contribution of non-blind following behavior were all strong; however, the marginal contribution of $X_{1}$ was less than that of $X_{2}$. The study findings are clearly in line with the existing literature $[9,17]$.

The H1.2 test results show that active participating following behavior $\left(X_{1}\right)$ and nonblind following behavior $\left(X_{2}\right)$ had positive effects on incremental creative work behavior $\left(Y_{2}\right)$. The marginal contribution of $X_{1}$ was 0.169 , and that of $X_{2}$ was 0.432 . That is to say, the marginal contribution of non-blind following behavior was far greater than that of active participating following behavior, and this value was also greater than its marginal contribution to radical creative work behavior.

The H1.3 test results show that both active participating following behavior and nonblind following behavior had a negative effect on non-creative routine work behavior. $X_{1}$ had a negative effect on $Y_{3}$ with a significance level of 0.05 , while $X_{2}$ also had a negative effect on $Y_{3}$, but this was not significant. Therefore, there was a negative correlation between active participating following behavior and non-creative routine work behavior: the more actively followers participated in work, the less they adopted non-creative routine work behavior. This study's results are in line with previous studies $[65,67]$.

\subsubsection{Discussion}

As shown in Table 4, the marginal contribution of $X_{1}$ to $Y_{1}$ was greater than that of $X_{1}$ to $Y_{2}$, and the marginal contribution of $X_{2}$ to $Y_{1}$ was less than that of $X_{2}$ to $Y_{2}$. This is a very enlightening result. From an intuitive perspective, "the more non-blind following behavior, the more radical creative behavior", which implies that "the independence and autonomy of followers are the key to creative work behavior".

However, the results of this study show that the effect of non-blind following behavior on incremental creative work behavior was greater than that on radical creative work behavior, and the effect of active participating following behavior on radical creative work behavior was greater than that on incremental creative work behavior. This indicates that the participation of followers is the key to creative work behavior. The current study findings are clearly in line with the existing literature [20,23].

Theoretically, followers' participation reflects the integration of followers' intrinsic motivation and extrinsic motivation, which is the key to creative work behavior. If a 
follower follows only verbally, but his behavior is not integrated into the work of the organization, then he cannot produce creative work behavior, let alone creative work performance. There is indeed a negative correlation between active participating following behavior and non-creative routine work behavior, which reveals that the more active followers participate in work, the less they will adopt non-creative routine work behavior, which also supports the previous results.

\subsection{Hypothesis Test Results and Discussion on the Moderating Role of Perceived Organizational Support}

\subsubsection{Test Results}

As observable from Tables 5 and $6, U_{1}$ had positive moderating effects on the relationship between $X_{1}$ and $Y_{1}$ and between $X_{1}$ and $Y_{2}$. $U_{1}$ had negative moderating effects on the relationship between $X_{2}$ and $Y_{1}$ and between $X_{2}$ and $Y_{2}$ with significance levels of 0.05 and 0.01. The positive moderating effects can be seen more clearly in Figures $3 a$ and $4 a$, and the negative moderating effects can be seen more clearly in Figures $3 b$ and $4 b$.

The statistical test results show that perceived organizational support had a positive reinforcement effect on both the effect of active participating following behavior on radical creative work behavior and the effect of active participating following behavior on incremental creative work behavior, while perceived organizational support had a negative moderating effect on both the effect of non-blind following behavior on radical creative work behavior and the effect of non-blind following behavior on incremental creative work behavior.

Thus, these findings lend full support for the moderating relationship between these two variables. These results are in conformity with the prior literature $[64,83]$ and reinforce the understanding that incremental creative work behavior relationships are more complicated than a linear connection.

As shown in Table 7, perceived organizational support had different effects on the relationship between the two dimensions of effective following behavior and non-creative routine work behavior. Perceived organizational support strengthened the negative relationship between active participating following behavior and non-creative routine work behavior but had no significant moderating effect on the relationship between non-blind following behavior and non-creative routine work behavior. The moderating effect of $U_{1}$ on the relationship between $X_{1}$ and $Y_{3}$ is shown in Figure 5 a.
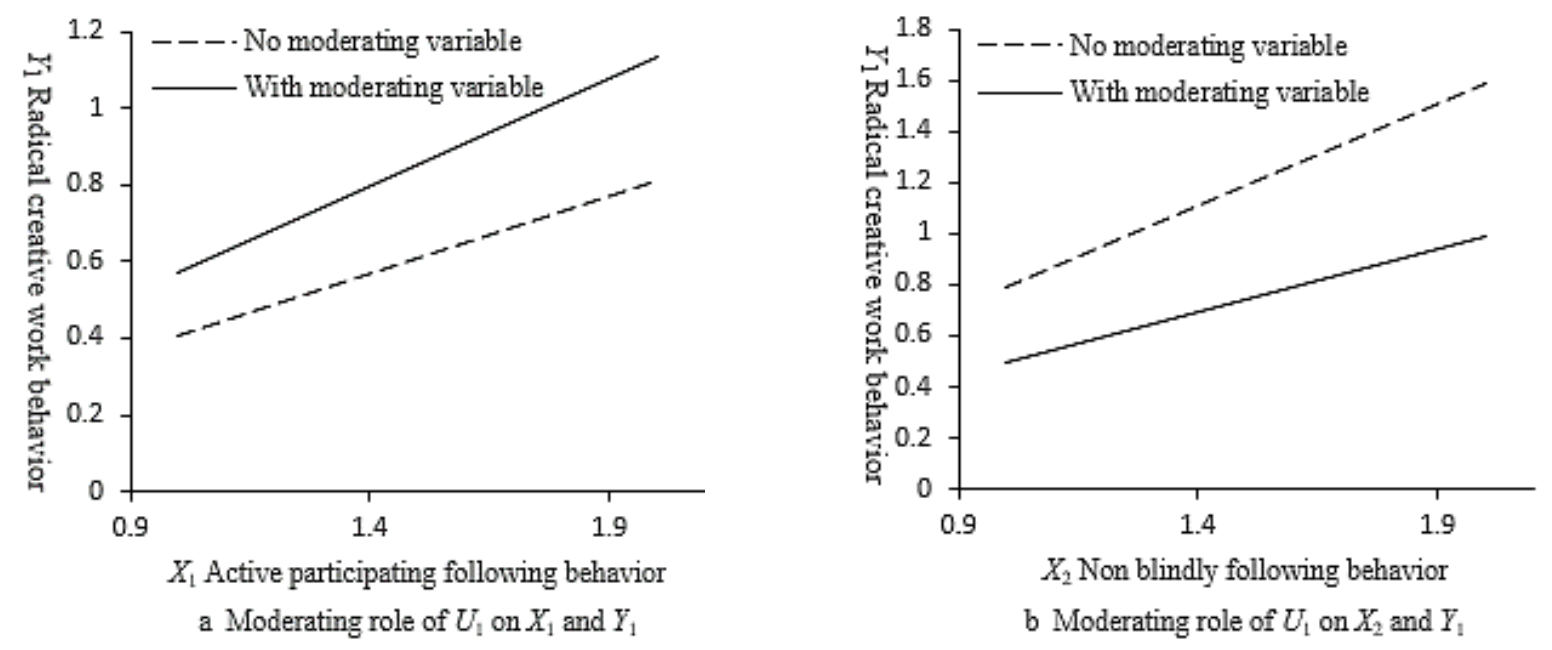

Figure 3. The moderating role of $U_{1}$ on the relationship between effective following behavior $X$ and $Y_{1}$. (a) Moderating role of $U_{1}$ on $X_{1}$ and $Y_{1} ;(\mathbf{b})$ Moderating role of $U_{1}$ on $X_{2}$ and $Y_{1}$. 

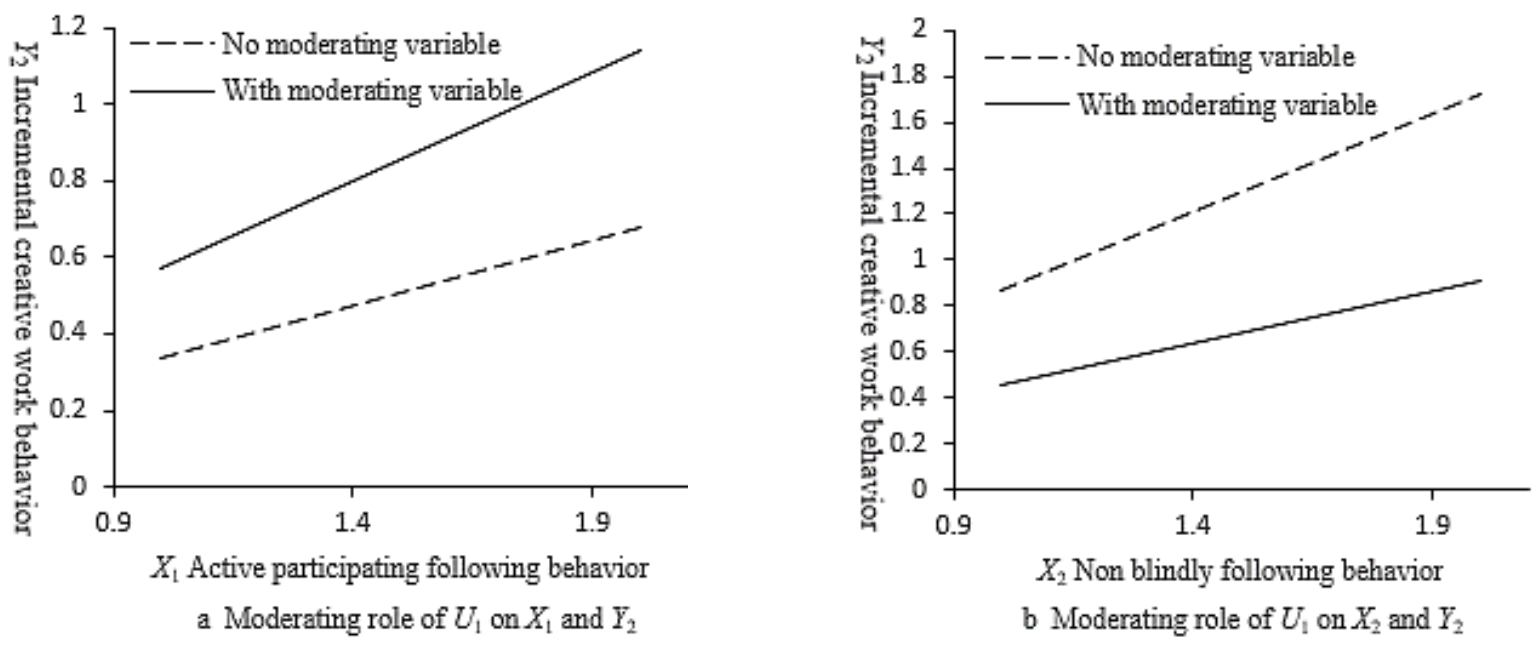

Figure 4. The moderating role of $U_{1}$ on the relationship between effective following behavior $X$ and $Y_{2}$. (a) Moderating role of $U_{1}$ on $X_{1}$ and $Y_{2} ;(\mathbf{b})$ Moderating role of $U_{1}$ on $X_{2}$ and $Y_{2}$.
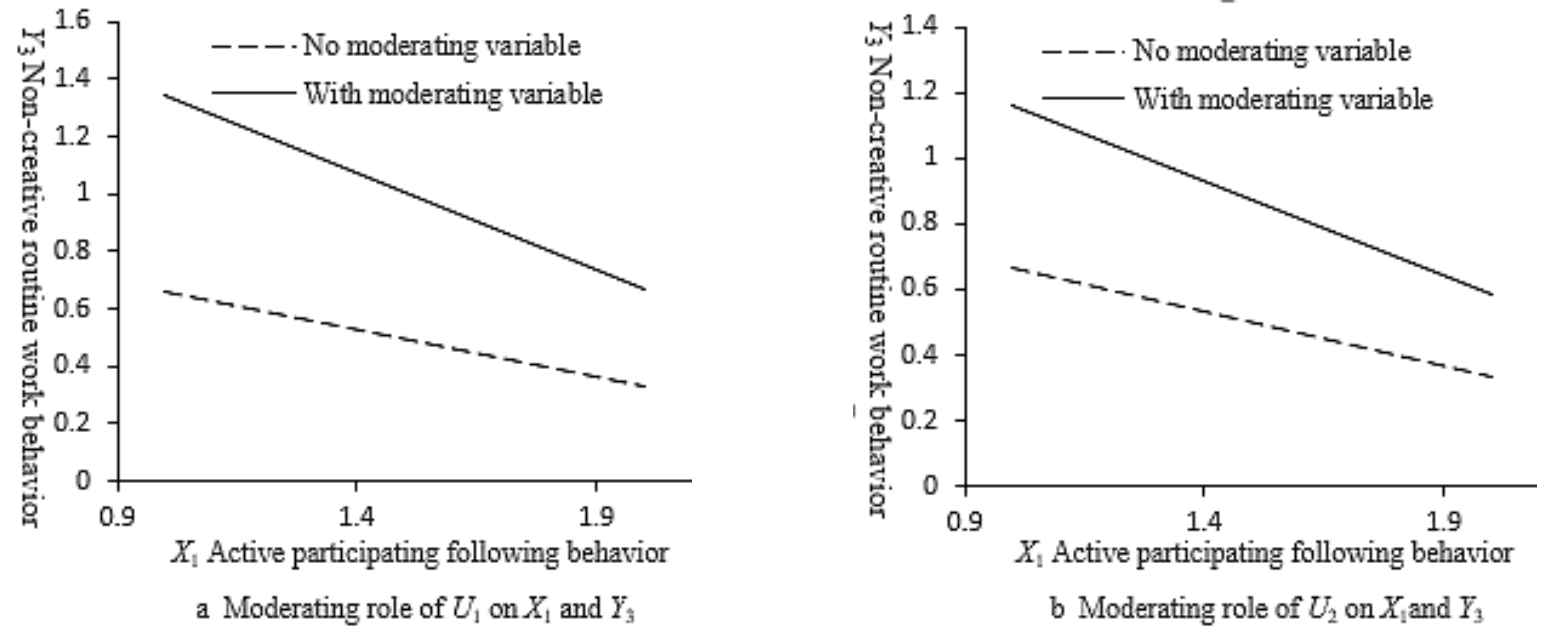

Figure 5. The moderating role of $U_{1}$ and $U_{2}$ on the relationship between $X_{1}$ and $Y_{3}$. (a) Moderating role of $U_{1}$ on $X_{1}$ and $Y_{3}$; (b) Moderating role of $U_{2}$ on $X_{1}$ and $Y_{3}$.

\subsubsection{Discussion}

Perceived organizational support will strengthen the relationship between active participating following behavior and creative work behavior and weaken the relationship between non-blind following behavior and creative work behavior. This result seems to be inconsistent with intuition, but it is true. Since when followers perceive organizational support, according to the social exchange theory, their following behavior will be more likely to participate in organizational activities, and they are more willing to use creative work behavior to repay organizational support.

People who adopt non-creative work behaviors in organizations are generally relatively insensitive. They either cannot perceive organizational support or can perceive organizational support. They cannot perceive the same organizational support, so they will adopt higher non-creative routine work behaviors; Once they are aware of organizational support, they are not willing to adopt non-creative routine work behavior and may be willing to adopt creative work behavior, so the sense of organizational support weakens the relationship between participating following behavior and non-creative work behavior. 


\subsection{Hypothesis Test Results and Discussion on the Moderating Role of Sustainable Leadership}

\subsubsection{Test Results}

As observable in Tables 5 and $6, U_{2}$ had positive moderating effects on the relationship between $X_{1}$ and $Y_{1}$ and between $X_{1}$ and $Y_{2}$ with significance levels of 0.05 , and Figures $6 \mathrm{a}$ and $7 \mathrm{a}$ show this relationship intuitively. $U_{2}$ had negative moderating effects on the relationship between $X_{2}$ and $Y_{1}$ and between $X_{2}$ and $Y_{2}$, with significance levels of 0.05 and 0.01 , and Figures $6 \mathrm{~b}$ and $7 \mathrm{~b}$ show this relationship intuitively.

The statistical test results show that sustainable leadership positively enhanced the effect of active participating following behavior to radical and incremental creative work behavior, while sustainable leadership weakened the effect of non-blindly following behavior to radical and incremental creative work behavior.

As can be seen in Table 7, sustainable leadership had different moderating effects on the relationship between the two dimensions of effective following behavior and noncreative routine work behavior. Sustainable leadership strengthened the negative relationship between active participating following behavior and non-creative routine work behavior but had no significant moderating effect on the relationship between non-blind following behavior and non-creative routine work behavior.

The moderating effect of $U_{2}$ on the relationship between $X_{1}$ and $Y_{3}$ is shown in Figure $5 \mathrm{~b}$. Therefore, these findings are in line with the existing literature on sustainable Leadership and that acting Creative Work Behavior tends to appreciate power, independence, risk tanking, and innovativeness [61].
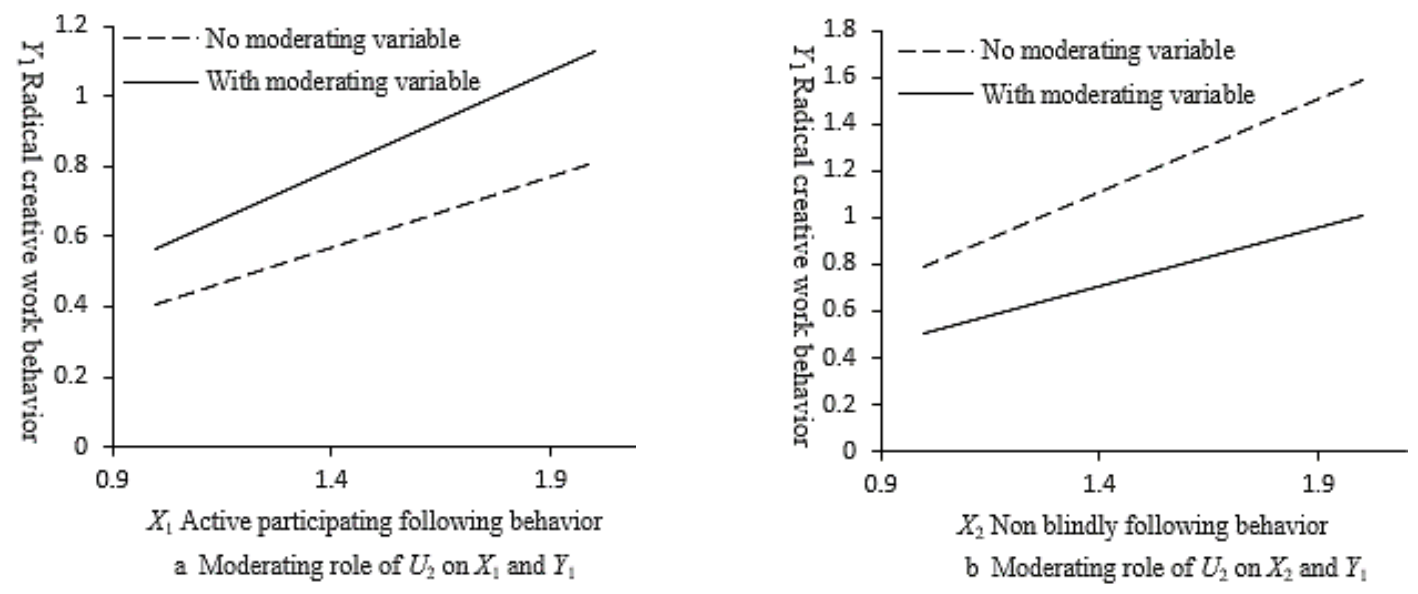

Figure 6. The moderating role of $U_{2}$ on the relationship between effective following behavior $X$ and $Y_{1}$. (a) Moderating role of $U_{2}$ on $X_{1}$ and $Y_{1}$; (b) Moderating role of $U_{2}$ on $X_{2}$ and $Y_{1}$.
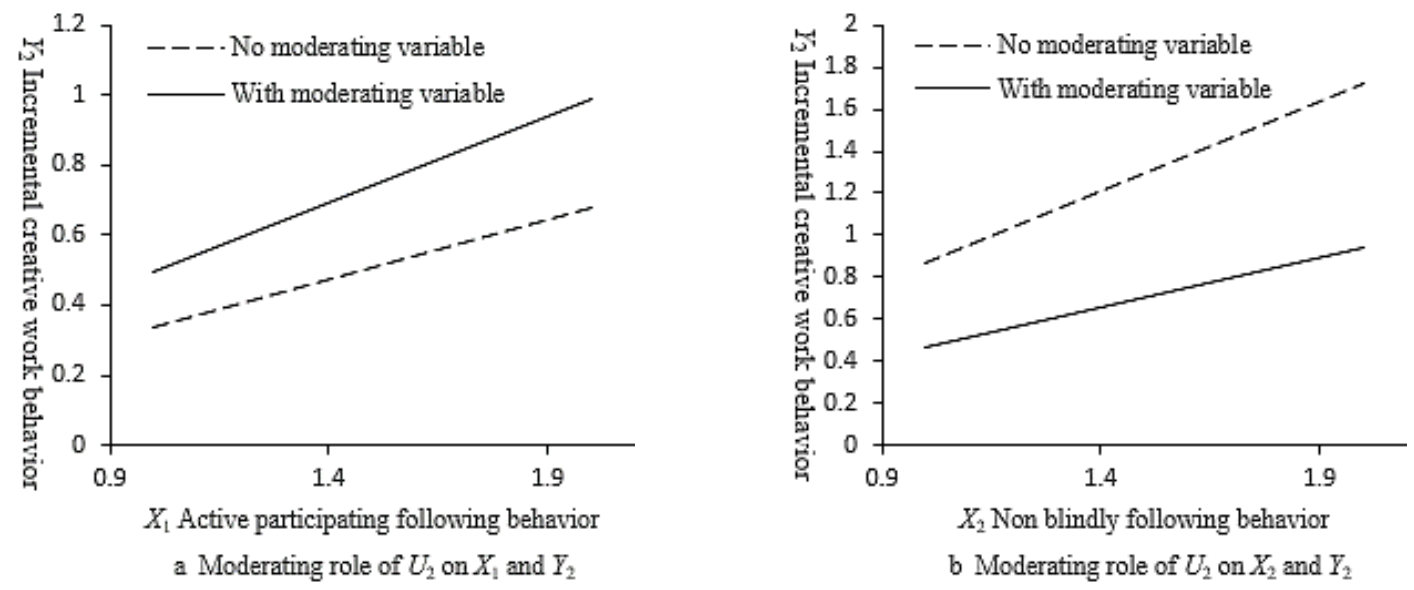

Figure 7. The moderating role of $U_{2}$ on the relationship between effective following behavior $X$ and $Y_{2}$. (a) Moderating role of $U_{2}$ on $X_{1}$ and $Y_{2} ;(\mathbf{b})$ Moderating role of $U_{2}$ on $X_{2}$ and $Y_{2}$. 


\subsubsection{Discussion}

Sustainable leadership will strengthen the relationship between active participation in following behavior and creative work behavior and weaken the relationship between non-blind following behavior and creative work behavior. That is to say, when followers perceive sustainable leadership, on the one hand, they are more willing to participate in the organization's activities and adopt creative work behavior in the activities, so leadership style has a positive effect on employees' work performance. On the other hand, creative behavior based on independence will weaken rather than increase. This is inconsistent with intuition, which raises a problem for us, that is, the relationship between non-blind obedience or independence and creative work behavior in the organization is weakened due to the existence of sustainable leadership. For those followers who were not actively involved and were completely non-blind in the organization, they either could not perceive the sustainability of leaders or were more reluctant to adopt non-creative routine work behavior in their work after they perceived leader sustainability.

\subsection{Management Implications}

First, the management implications of the positive correlations between followers' effective following behavior (active participating following behavior and non-blind following behavior) and followers' creative work behavior (radical and incremental) are as follows. The stronger the followers' active participation behavior was, the more conducive to their radical (original) creative work behavior and, secondly, to their incremental creative work behavior [11,19].

At the same time, followers should also have a certain degree of the non-blind following. The active participating following behavior is a key behavior, while non-blind following behavior had a "degree", and non-blind following behavior was not better when higher. Therefore, in management, we should pay attention to the balance between followers' active participating following behavior and non-blind following behavior [18,72].

To stimulate followers' creative work behavior, the most important thing is to involve employees in the activities of the organization. The stronger the participation, the more conducive to creative behavior; In the Chinese context, increasing followers' participation and controlling their non-blind obedience are more conducive to the generation of employees' creative work behavior.

Second, perceived organizational support and sustainable leadership strengthened the relationship between follower active participating following behavior and creative work behavior and weakened the relationship between non-blind following behavior and creative work behavior. The management implications are as follows: we can strengthen the effect of participatory following behavior on creative work behavior by increasing followers' perceived organizational support and leadership sustainability and increase the effect of non-blind following behavior on creative work behavior by reducing followers' perceived organizational support and leadership sustainability [60].

Third, followers' non-creative work behavior was negatively correlated with their active participating following behavior and had no significant correlation with their nonblind following behavior $[24,54]$. This indicates that, when followers were unwilling to adopt active participating following behavior, their work behavior was often non-creative routine work behavior. Followers who adopted non-creative routine work behavior in the organization could not perceive the organizational support and sustainable leadership, and the reason is that they adopted non-effective following behavior [65].

The management implications of the results are that, in order to mobilize the creative work motivation of all followers (employees) and make them have a certain degree of creativity in their work, we should, first, increase their internal following motivation, improve their active participating following behavior, have them produce effective following behavior, and then derive creative work behavior; and secondly, have these followers perceive organizational support and leadership sustainability, and adjust the effect of effective following behavior on creative work behavior. 


\subsection{Limitations and Prospects of This Study}

Certain shortcomings and limitations exist in this study. First, although the collected samples met the requirements of randomness, the sample size was still somewhat insufficient. Therefore, the research conclusions require further verification by more samples. Secondly, the model constructed in this paper involves effective following behavior and followers' creative work behavior (there are three dimensions), and the industry characteristics, age, and gender were not considered in the hypothesis.

The general conclusions were obtained based on the samples that were equally treated despite being from different industries. However, in terms of following behavior and creative work behavior, there are obvious differences among different types of organizations, different ages, and different genders.

Thirdly, the deficiency of research methods, the problems involved in this paper, and the hypotheses produced by these problems can be tested by the method of experimental comparison, but this paper did not do this work.

The above three points are the biggest limitations of this paper, but this is also a problem that can be further studied. Therefore, on the basis of our present work, we can further expand the sample size, design more detailed information, such as organizational characteristics and employee age and gender, when collecting a large number of samples, and take industry characteristics as the corresponding variables (which can be control variables or moderating variables) when establishing models and making assumptions.

Intuitively, the relationship between employee following behavior and creative work behavior is different between military organizations and university organizations, traditional industrial organizations, and high-tech industrial organizations. People of different ages have different cognitions of life, organizations, and society, and thus, the relationships between their following behavior and creative work behavior are also different. At the same time, the interactions of these sample information variables with sustainable leadership and organizational support may be different. If we use the method of experimental comparison, we can make an experimental study on the creative work behavior of people with different following motivations. Therefore, there may be many interesting results to be obtained by studying these problems.

Author Contributions: Conceptualization, X.W.; methodology, X.W. and L.A.; software, X.W., N.Y., N.M. and Y.G.; validation, X.W., N.Y., N.M. and Y.G.; investigation, X.W., N.Y., N.M. and Y.G.; resources, X.W. and L.A.; data curation, X.W., L.A., N.Y., N.M. and Y.G.; writing-original draft preparation, X.W., N.Y. and N.M.; writing-review and editing, X.W. and L.A.; visualization, X.W., N.Y., N.M. and L.A.; supervision, L.A. All authors have read and agreed to the published version of the manuscript.

Funding: This research was funded by the National Natural Science Foundation of China, grant number 71171159 and Postgraduate Research.

Institutional Review Board Statement: All procedures followed in this research were in accordance with the ethical standards of the responsible committee on human experimentation (Northwest University, Xi'an 710127, China) and with the Helsinki Declaration of 1975, as revised in 2000. This approval was taken on 25 June 2020.

Informed Consent Statement: Written informed consent was obtained from all participants to be included in the study.

Data Availability Statement: The quantitative data used to support the findings of this study are included within the article.

Conflicts of Interest: The authors declare no conflict of interest. 


\section{References}

1. De Sousa Jabbour, A.B.L.; Vazquez-Brust, D.; Jabbour, C.J.C.; Ribeiro, D.A. The interplay between stakeholders, resources and capabilities in climate change strategy: Converting barriers into cooperation. Bus. Strategy Environ. 2020, 29, 1362-1386. [CrossRef]

2. Hallinger, P.; Suriyankietkaew, S. Science mapping of the knowledge base on sustainable leadership, 1990-2018. Sustainability 2018, 10, 4846. [CrossRef]

3. Iqbal, Q.; Hassan, S.H. Green management matters: Green human resource management as blue ocean strategy. In Firms' Strategic Decisions. Theoretical and Empirical Findings; Bentham Science Publishers: Sharjah, United Arab Emirates, 2018; Volume 3, pp. 214-236.

4. Khan, S.A.R.; Jian, C.; Zhang, Y.; Golpîra, H.; Kumar, A.; Sharif, A. Environmental, social and economic growth indicators spur logistics performance: From the perspective of South Asian Association for Regional Cooperation countries. J. Clean. Prod. 2019, 214, 1011-1023. [CrossRef]

5. Burawat, P. The relationships among transformational leadership, sustainable leadership, lean manufacturing and sustainability performance in Thai SMEs manufacturing industry. Int. J. Qual. Reliab. Manag. 2019, 36, 1014-1036. [CrossRef]

6. Lynch, B.M.; McCance, T.; McCormack, B.; Brown, D. The development of the Person-Centred Situational Leadership Framework: Revealing the being of person-centredness in nursing homes. J. Clin. Nurs. 2018, 27, 427-440. [CrossRef] [PubMed]

7. Dvir, T.; Shamir, B. Follower developmental characteristics as predicting transformational leadership: A longitudinal field study. Leadersh. Q. 2003, 14, 327-344. [CrossRef]

8. Amui, L.B.L.; Jabbour, C.J.C.; de Sousa Jabbour, A.B.L.; Kannan, D. Sustainability as a dynamic organizational capability: A systematic review and a future agenda toward a sustainable transition. J. Clean. Prod. 2017, 142, 308-322. [CrossRef]

9. Miao, Q.; Eva, N.; Newman, A.; Cooper, B. CEO entrepreneurial leadership and performance outcomes of top management teams in entrepreneurial ventures: The mediating effects of psychological safety. J. Small Bus. Manag. 2019, 57, 1119-1135. [CrossRef]

10. Carsten, M.K.; Uhl-Bien, M. Ethical followership: An examination of followership beliefs and crimes of obedience. J. Leadersh Organ. Stud. 2013, 20, 49-61. [CrossRef]

11. Bowers, D.G.; Seashore, S.E. Predicting organizational effectiveness with a four-factor theory of leadership. Adm. Sci. Q. 1966, 11, 238-263. [CrossRef]

12. Hersey, P.; Blanchard, K.H. Life cycle theory of leadership. Train. Dev. J. 1969, 23, 26-34.

13. Lowe, K.B.; Gardner, W.L. Ten years of the leadership quarterly: Contributions and challenges for the future. Leadersh. Q. 2000, 11, 459-514. [CrossRef]

14. Rehman, S.; Sami, A.; Haroon, A.; Irfan, A. Impact Of Sustainable Leadership Practices On Public Sector Organizations: A Systematic Review of Past Decade. J. Public Value Adm. Insights 2019, 2, 1-5. [CrossRef]

15. Margolis, J. Multiple team membership: An integrative review. Small Group Res. 2020, 51, 48-86. [CrossRef]

16. Kozioł-Nadolna, K. The Role of a Leader in Stimulating Innovation in an Organization. Adm. Sci. 2020, 10, 59. [CrossRef]

17. Iqbal, Q.; Hassan, S.H.; Akhtar, S.; Khan, S. Employee's green behavior for environmental sustainability: A case of banking sector in Pakistan. World J. Sci. Technol. Sustain. Dev. 2018, 15, 118-130. [CrossRef]

18. McCormick, B.W.; Guay, R.P.; Colbert, A.E.; Stewart, G.L. Proactive personality and proactive behaviour: Perspectives on person-situation interactions. J. Occup. Organ. Psychol. 2019, 92, 30-51. [CrossRef]

19. Li, G.; Wang, X.; Wu, J. How scientific researchers form green innovation behavior: An empirical analysis of China's enterprises. Technol. Soc. 2019, 56, 134-146. [CrossRef]

20. Guan, H.; Zhang, Z.; Zhao, A.; Jia, J.; Guan, S. Research on Innovation Behavior and Performance of New Generation Entrepreneur Based on Grounded Theory. Sustainability 2019, 11, 2883. [CrossRef]

21. Yang, J.; Gu, J.; Liu, H. Servant leadership and employee creativity: The roles of psychological empowerment and work-family conflict. Curr. Psychol. 2019, 38, 1417-1427. [CrossRef]

22. Martin, R.; Guillaume, Y.; Thomas, G.; Lee, A.; Epitropaki, O. Leader-member exchange (LMX) and performance: A meta-analytic review. Pers. Psychol. 2016, 69, 67-121. [CrossRef]

23. Harris, K.J.; Wheeler, A.R.; Kacmar, K.M. Leader-member exchange and empowerment: Direct and interactive effects on job satisfaction, turnover intentions, and performance. Leadersh. Q. 2009, 20, 371-382. [CrossRef]

24. Akcay Kasapoglu, O. Leadership and Organization for the Companies in the Process of Industry 4.0 Transformation. Int. J. Organ. Leadersh. 2018, 7, 300-308. [CrossRef]

25. Chen, X.; Weerathunga, P.; Nurunnabi, M.; Kulathunga, K.; Samarathunga, W. Influences of Behavioral Intention to Engage in Environmental Accounting Practices for Corporate Sustainability: Managerial Perspectives from a Developing Country. Sustainability 2020, 12, 5266. [CrossRef]

26. Kelley, R.E. In Praise of Followers; Harvard Business Review Case Services: Brighton, MA, USA, 1988.

27. Chaleff, I. The Courageous Follower: Standing Up to \& for Our Leaders; Berrett-Koehler Publishers: Oakland, CA, USA, 2009.

28. Baker, S.D. Followership: The theoretical foundation of a contemporary construct. J. Leadersh. Organ. Stud. 2007, 14, 50-60. [CrossRef]

29. Lee, C.; Hallak, R.; Sardeshmukh, S.R. Creativity and innovation in the restaurant sector: Supply-side processes and barriers to implementation. Tour. Manag. Perspect. 2019, 31, 54-62. [CrossRef] 
30. Madjar, N.; Greenberg, E.; Chen, Z. Factors for radical creativity, incremental creativity, and routine, noncreative performance. J. Appl. Psychol. 2011, 96, 730. [CrossRef]

31. Dewar, R.D.; Dutton, J.E. The adoption of radical and incremental innovations: An empirical analysis. Manag. Sci. 1986, 32, 1422-1433. [CrossRef]

32. Benner, M.J.; Tushman, M.L. Exploitation, exploration, and process management: The productivity dilemma revisited. Acad. Manag. Rev. 2003, 28, 238-256. [CrossRef]

33. Gupta, A.K.; Smith, K.G.; Shalley, C.E. The interplay between exploration and exploitation. Acad. Manag. J. 2006, 49, 693-706. [CrossRef]

34. Amabile, T.M.; Conti, R.; Coon, H.; Lazenby, J.; Herron, M. Assessing the work environment for creativity. Acad. Manag. J. 1996, 39, 1154-1184.

35. Borman, W.C.; Motowidlo, S.J. Task performance and contextual performance: The meaning for personnel selection research. Hum. Perform. 1997, 10, 99-109. [CrossRef]

36. Adams, J.S. Inequity in social exchange. In Advances in Experimental Social Psychology; Elsevier: Amsterdam, The Netherlands, 1965; Volume 2, pp. 267-299.

37. Homans, G.C. Social Behavior: Its Elementary Forms; Harcourt Brace: San Diego, CA, USA, 1974.

38. Crisp, R.J.; Turner, R.N. Essential Social Psychology; SAGE: Thousand Oaks, CA, USA, 2020.

39. Dhar, R.L. Ethical leadership and its impact on service innovative behavior: The role of LMX and job autonomy. Tour. Manag. 2016, 57, 139-148. [CrossRef]

40. Durst, S.; Zieba, M. Mapping knowledge risks: Towards a better understanding of knowledge management. Knowl. Manag. Res. Pract. 2019, 17, 1-13. [CrossRef]

41. Ford, C.M. A theory of individual creative action in multiple social domains. Acad. Manag. Rev. 1996, 21, 1112-1142. [CrossRef]

42. Fischer, C.; Malycha, C.P.; Schafmann, E. The Influence of Intrinsic Motivation and Synergistic Extrinsic Motivators on Creativity and Innovation. Front. Psychol. 2019, 10, 137. [CrossRef]

43. Ansari, N.Y.; Siddiqui, S.H.; Farrukh, M. The effect of high performance work practices on employee innovative behavior: The mediating role of job embeddedness. Int. J. Contemp. Econ. Adm. Sci. 2018, 8, 64-88.

44. Gottfredson, R.K.; Wright, S.L.; Heaphy, E.D. A critique of the leader-member exchange construct: Back to square one. Leadersh. Q. 2020, 31, 101385. [CrossRef]

45. Gong, Y.; Wu, J.; Song, L.J.; Zhang, Z. Dual tuning in creative processes: Joint contributions of intrinsic and extrinsic motivational orientations. J. Appl. Psychol. 2017, 102, 829. [CrossRef]

46. Unsworth, K.L.; Clegg, C.W. Why do employees undertake creative action? J. Occup. Organ. Psychol. 2010, 83, 77-99. [CrossRef]

47. Kuvaas, B.; Buch, R. Leader-member exchange relationships and follower outcomes: The mediating role of perceiving goals as invariable. Hum. Resour. Manag. 2018, 57, 235-248. [CrossRef]

48. Miron, E.; Erez, M.; Naveh, E. Do personal characteristics and cultural values that promote innovation, quality, and efficiency compete or complement each other? J. Organ. Behav. 2004, 25, 175-199. [CrossRef]

49. Lee, A.; Gerbasi, A.; Schwarz, G.; Newman, A. Leader-member exchange social comparisons and follower outcomes: The roles of felt obligation and psychological entitlement. J. Occup. Organ. Psychol. 2019, 92, 593-617. [CrossRef]

50. Wilson, K.S.; Sin, H.-P.; Conlon, D.E. What about the leader in leader-member exchange? The impact of resource exchanges and substitutability on the leader. Acad. Manag. Rev. 2010, 35, 358-372.

51. Eisenberger, R.; Huntington, R.; Hutchison, S.; Sowa, D. Perceived organizational support. J. Appl. Psychol. 1986, 71, 500. [CrossRef]

52. Kraimer, M.L.; Wayne, S.J. An examination of perceived organizational support as a multidimensional construct in the context of an expatriate assignment. J. Manag. 2004, 30, 209-237. [CrossRef]

53. Ali, F.H.; Rizavi, S.S.; Ahmed, I.; Rasheed, M. Effects of perceived organizational support on organizational citizenship behaviorSequential mediation by well-being and work engagement. J. Punjab Univ. Hist. Soc. 2018, 31, 111-131.

54. Asgari, A.; Mezginejad, S.; Taherpour, F. The role of leadership styles in organizational citizenship behavior through the mediation of perceived organizational support and job satisfaction. Innovar 2020, 30, 87-98. [CrossRef]

55. Gilson, L.L.; Madjar, N. Radical and incremental creativity: Antecedents and processes. Psychol. Aesthet. Creat. Arts 2011, 5, 21. [CrossRef]

56. Bal, P.M.; Hofmans, J.; Polat, T. Breaking psychological contracts with the burden of workload: A weekly study of job resources as moderators. Appl. Psychol. 2017, 66, 143-167. [CrossRef]

57. Murthy, R.K. Perceived organizational support and work engagement. Int. J. Appl. Res. 2017, 3, 738-740.

58. Islam, T.; Khan, M.M.; Khawaja, F.N.; Ahmad, Z. Nurses' reciprocation of perceived organizational support: The moderating role of psychological contract breach. Int. J. Hum. Rights Healthc. 2017, 10, 123-131. [CrossRef]

59. Nembhard, I.M.; Edmondson, A.C. Making it safe: The effects of leader inclusiveness and professional status on psychological safety and improvement efforts in health care teams. J. Organ. Behav. 2006, 27, 941-966. [CrossRef]

60. Carmeli, A.; Reiter-Palmon, R.; Ziv, E. Inclusive leadership and employee involvement in creative tasks in the workplace: The mediating role of psychological safety. Creat. Res. J. 2010, 22, 250-260. [CrossRef] 
61. Teece, D.J. Technological innovation and the theory of the firm: The role of enterprise-level knowledge, complementarities, and (dynamic) capabilities. In Handbook of the Economics of Innovation; Elsevier: Amsterdam, The Netherlands, 2010; Volume 1, pp. 679-730.

62. Akinola, M.; Kapadia, C.; Lu, J.G.; Mason, M.F. Incorporating physiology into creativity research and practice: The effects of bodily stress responses on creativity in organizations. Acad. Manag. Perspect. 2019, 33, 163-184. [CrossRef]

63. Hobfoll, S.E.; Halbesleben, J.; Neveu, J.-P.; Westman, M. Conservation of resources in the organizational context: The reality of resources and their consequences. Annu. Rev. Organ. Psychol. Organ. Behav. 2018, 5, 103-128. [CrossRef]

64. Sung, S.Y.; Antefelt, A.; Choi, J.N. Dual effects of job complexity on proactive and responsive creativity: Moderating role of employee ambiguity tolerance. Group Organ. Manag. 2017, 42, 388-418. [CrossRef]

65. Randel, A.E.; Galvin, B.M.; Shore, L.M.; Ehrhart, K.H.; Chung, B.G.; Dean, M.A.; Kedharnath, U. Inclusive leadership: Realizing positive outcomes through belongingness and being valued for uniqueness. Hum. Resour. Manag. Rev. 2018, 28, 190-203. [CrossRef]

66. Shore, L.M.; Cleveland, J.N.; Sanchez, D. Inclusive workplaces: A review and model. Hum. Resour. Manag. Rev. 2018, 28, 176-189. [CrossRef]

67. Guo, Y.; Zhu, Y.; Zhang, L. Inclusive leadership, leader identification and employee voice behavior: The moderating role of power distance. Curr. Psychol. 2020, 39, 1-10. [CrossRef]

68. Kelley, R.E. The Power of Followership: How to Create Leaders People Want to Follow, and Followers Who Lead Themselves; Broadway Business: New York, NY, USA, 1992.

69. Mumford, M.D.; Gustafson, S.B. Creativity syndrome: Integration, application, and innovation. Psychol. Bull. 1988, 103, 27. [CrossRef]

70. Amabile, T.M.; Pratt, M.G. The dynamic componential model of creativity and innovation in organizations: Making progress, making meaning. Res. Organ. Behav. 2016, 36, 157-183. [CrossRef]

71. Sternberg, R.J. The nature of creativity. Creat. Res. J. 2006, 18, 87.

72. Sternberg, R.J. A propulsion model of types of creative contributions. Rev. Gen. Psychol. 1999, 3, 83-100. [CrossRef]

73. Eisenberger, R.; Fasolo, P.; Davis-LaMastro, V. Perceived organizational support and employee diligence, commitment, and innovation. J. Appl. Psychol. 1990, 75, 51. [CrossRef]

74. McMillan, R. Customer satisfaction and organizational support for service providers. Ph.D. Thesis, University of Florida, Gainesville, FL, USA, 1997.

75. Lee, S.H.; Jeong, D.Y. Job insecurity and turnover intention: Organizational commitment as mediator. Soc. Behav. Personal. Int. J. 2017, 45, 529-536. [CrossRef]

76. Tabachnick, B.; Fiddell, L. Using Multivariate Statistics; Pearson Education: Boston, MA, USA, 2007.

77. Hair, J.F. Multivariate Data Analysis; Pearson: London, UK, 2009.

78. Steiger, J.H. Understanding the limitations of global fit assessment in structural equation modeling. Personal. Individ. Differ. 2007, 42, 893-898. [CrossRef]

79. Anderson, J.C.; Gerbing, D.W. Structural equation modeling in practice: A review and recommended two-step approach. Psychol. Bull. 1988, 103, 411. [CrossRef]

80. Fornell, C.; Larcker, D.F. Evaluating structural equation models with unobservable variables and measurement error. J. Mark. Res. 1981, 18, 39-50. [CrossRef]

81. Chang, S.-J.; van Witteloostuijn, A.; Eden, L. From the Editors: Common Method Variance in International Business Research; Springer: Berlin/Heidelberg, Germany, 2010.

82. Harman, H.H. Modern Factor Analysis; University of Chicago Press: Chicago, IL, USA, 1976.

83. Nishii, L.H. The benefits of climate for inclusion for gender-diverse groups. Acad. Manag. J. 2013, 56, 1754-1774. [CrossRef] 